\section{(6) OPEN ACCESS}

\title{
The use of abstract paintings and narratives to foster reflective capacity in medical educators: a multinational faculty development workshop
}

\author{
Khaled Karkabi, ${ }^{1,2}$ Hedy S Wald, ${ }^{3}$ Orit Cohen Castel ${ }^{2,4}$
}

\begin{abstract}
'Department of Family Medicine, Clalit Health Services, Haifa and Western Galilee District, Haifa, Israel ${ }^{2}$ The Division of Family Medicine, The Ruth \& Bruce Rappaport Faculty of Medicine, Technion-Israel Institute of Technology, Haifa, Israel ${ }^{3}$ Department of Family Medicine, Warren Alpert Medical School of Brown University, Providence, Rhode Island, USA ${ }^{4}$ The Cheryl Spencer Department of Nursing, University of Haifa, Haifa, Israel
\end{abstract}

Correspondence to Dr Khaled Karkabi, Family Medicine, Rappaport Faculty of Medicine, Technion, Israel Institute of Technology, Pob 8273, Haifa 31082, Israel; khaledka@clalit.org.il, khaled.karkabi@gmail.com

Received 15 March 2013 Revised 6 November 2013 Accepted 7 November 2013 Published Online First 22 November 2013

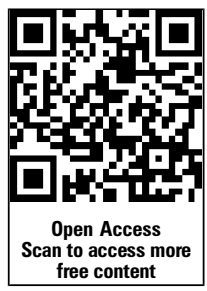

To cite: Karkabi K, Wald HS, Cohen Castel 0. Med Humanit 2014:40 44-48.

\begin{abstract}
Reflective capacity is integral to core healthcare professional practice competencies. Reflection plays a central role in teacher education as reflecting on teaching behaviours with critical analysis can potentially improve teaching practice. The humanities including narrative and the visual arts can serve as a valuable tool for fostering reflection. We conducted a multinational faculty development workshop aiming to enhance reflective capacity in medical educators by using a combination of abstract paintings and narratives. Twenty-three family physicians or physicians-in-training from 10 countries participated in the workshop. Qualitative assessment of the workshop showed that the combined use of art and narrative was well received and perceived as contributing to the reflective exercise. Participants generally felt that viewing abstract paintings had facilitated a valuable mood transformation and prepared them emotionally for the reflective writing. Our analysis found that the following themes emerged from participants' responses: (1) narratives from different countries are similar; (2) the use of art helped access feelings; (3) viewing abstract paintings facilitated next steps; (4) writing reflective narratives promoted examination of educational challenges, compassion for self and other, and building an action plan; and (5) sharing of narrative was helpful for fostering active listening and appreciating multiple perspectives. Future research might include comparing outcomes for a group participating in arts-narrative-based workshops with those of a control group using only reflective narrative or in combination with figurative art, and implementing a combination of qualitative and quantitative methods of assessment.
\end{abstract}

\section{INTRODUCTION}

\section{Reflective capacity in medical education}

Reflective capacity, that is, the critical analysis of knowledge and experience to achieve deeper meaning and understanding, guiding future behaviour $^{1}$ is integral to core healthcare professional practice competencies (eg, the Accreditation Council for Graduate Medical Education (ACGME) of the $\mathrm{USA}^{2}$ and the General Medical Council (GMC) of the $\mathrm{UK}^{3}$ ). Schon's fundamental processes of reflection in- and on-action ${ }^{4}$ integrated with affective experience 5 for deeper learning are essential for mindful practice. ${ }^{6}$ The use of reflection fosters empathy ${ }^{7}$ and practical wisdom ${ }^{6}$ and can help guide healthcare practitioners as they encounter the complexity inherent to clinical practice. ${ }^{8}$ Reflection is associated with effective use of feedback in medical education ${ }^{9}$ and the value of training faculty as 'reflective coaches' has been emphasised. ${ }^{10}{ }^{11}$ Reflection in general has a central role in teacher education ${ }^{12}$ as the art of 'paying attention', ${ }^{13}$ and reflecting on teaching behaviours with critical analysis can potentially improve teaching practice. ${ }^{12}$ Reflection is not necessarily intuitive for learners or teachers, thus medical educators and faculty development programme developers are challenged to devise innovative pedagogy to promote reflective capacity development. ${ }^{8}$ The humanities including narrative literature ${ }^{14}$ and reflective writing, ${ }^{15-17}$ and the visual arts ${ }^{18-20}$ can serve as valuable avenues for fostering reflection. ${ }^{21}$

\section{Narrative and reflection in medical education}

Under the umbrella of narrative medicine, the study of literature (with narrative skills training) and reflective writing ${ }^{17}$ can promote reflection, building the skills of observation and interpretation and nurturing empathic attention to patients. ${ }^{22}$ Through the use of physician and studentgenerated texts, narrative competency processes of attention, representation and affiliation (with colleagues and patients) can be developed, mirroring clinical practice. ${ }^{17}$ Thinking with stories can teach phronesis or "constant self-awareness as a moral actor". ${ }^{23}$ The use of the written word to represent perceptions, with narrative described as an "edifice", ${ }^{17}$ provides an opportunity for deeper reflection. ${ }^{15}$ The development of emotional selfreflective ability within medical education has been described in memoirs and poetry. ${ }^{24}$ 'Interactive' reflective writing with integration of written feedback from faculty has been described as fostering learners' development of more sophisticated reflection skills. ${ }^{25}{ }^{26}$ In addition to cultivating insights into the process of patient care and promoting student-practitioner well-being, reflective writing in small group process within medical education can promote reflective self-assessment, a component of professional development. ${ }^{27}$ Furthermore, the relationship between reflective writing and professional development during the process of teacher education is well documented. ${ }^{28}$ The process of narrative reflective practice (physician-trainees and physicians sharing stories and peer group narrative inquiry; narrative 'triggers' for reflection) ${ }^{29}$ facilitates meaning-making within clinical and teaching experience for shaping professional identity. ${ }^{30}$

\section{Arts and reflection in medical education}

Within medical education, the visual arts serve to enhance observational skills, ${ }^{31}{ }^{32}$ improve diagnostic skills, ${ }^{33} 34$ increase the span of listening to the 
patient, ${ }^{35}$ and deepen compassion for suffering. ${ }^{36}$ The formal implementation of arts curricula-as a component of medical humanities-for enhancing reflection in medical education is increasing in prevalence. ${ }^{18}{ }^{37-39}$ According to Hurwitz, the arts help "order, illuminate, and deepen experience", by working through "reflective and imaginative processes". 40

Various arts modalities and combinations of modalities have been employed for fostering reflection. An interactive exhibition of photographs (of an ambiguous nature) was used as a catalyst for healthcare professionals', patients' and families' reflection on feelings, spirituality, the illness process, and views of mortality in a healthcare context. ${ }^{20}$ Multimedia including use of visual methodologies in digital storytelling was found to stimulate reflection learning in medical students. ${ }^{41}$ Images of older adults were found to evoke emotional responses and foster critical reflection in a nursing education study of photo elicitation. ${ }^{42}$ The combination of viewing paintings and writing a short story to enhance understanding of human suffering has been successfully implemented in workshops for healthcare providers and medical educators. ${ }^{43}$ These combined modalities (writing narratives based on paintings) were found to stimulate students to reflect on their own experience with patients and to examine their emotions, feelings and actions. ${ }^{18}$

\section{The viewer's experience}

The arts involve the viewer directly, stretch the imagination, increase emotional self-awareness, and deepen affective resonance. ${ }^{43}$ In general, when Downie was posed the question: "How do we learn from arts?", he responded: "We learn from arts by imaginative identification with the situations or characters depicted, and by having our imaginations stretched through being made to enter into unfamiliar situations or to see points of view other than our own". ${ }^{44}$ Individuals look at art and react to it, each in his/her own way. The manner in which people look at art is affected by a whole series of learnt assumptions about art with regard to beauty, truth, genius, civilisation, form, status, taste, etc. ${ }^{45}$ Our reaction to art may vary with age, place, time and state of mind. The process of looking at paintings engages the intellect and emotions, that is, cognitive and affective components. Aesthetic experiences, in general, have been described as providing cognitive and affective processing, hypothesised to be art-specific, and in many cases both pleasing and self-rewarding. ${ }^{46}$ The emerging discipline of neuroesthetics ${ }^{47}$ may offer some insights into the neurological bases of the aesthetic experience, such as the blurred imagery of impressionist paintings affecting the brain's amygdala, a phenomenon which may contribute to viewers pervasively finding such pieces to be moving (given the amygdala's crucial role in emotions). ${ }^{48}$

As we embarked on designing a faculty development programme to enhance reflection, we deliberately selected the medium of abstract art in contrast to prior work (and more popular use) with figurative paintings in medical education. ${ }^{31-33}$ In its purest form in Western art, abstract art is "one without a recognizable subject, one which doesn't relate to anything external or try to 'look like' something. Instead the color and form are the subject of the abstract painting. It's completely nonobjective or non-representational". ${ }^{49}$ While the reaction of the viewer to abstract painting might vary widely (as with figurative art), the viewer is not directed to an image or subject, and she/ he has the liberty to flow with her imagination and emotions. Interestingly, the emotional state associated with aesthetic experiences has been hypothesised, at least in some cases, to extend to an experience of flow, ${ }^{50}$ described as a strong, positive emotional state which bears strong, intrinsic motivational potential. $^{46}$

Our decision to use abstract paintings was based on the idea that such viewing can facilitate viewers' connecting with the self and their own inner worlds, thus engaging both cognitive and affective abilities. We hypothesised that such an exercise would facilitate the transition to the next step, writing a reflective narrative.

\section{Faculty development to promote reflection}

Faculty development for optimising facilitated reflection within medical education has been advocated. ${ }^{51}$ Such initiatives include building a community of reflective practice through faculty development for enhancing feedback to medical students' reflective narratives ${ }^{52}$ and through sessions which incorporate peer group collaborative reflection on interprofessional faculty's self-generated reflective narratives. ${ }^{38}$ Engaging in the process of guided reflection on students' reflective narratives can facilitate faculty's capacity to serve as reflective role models through an intersubjective process of transformative growth" ${ }^{17}$ since "the student is no longer the person who wrote the reflective narrative, neither is the teacher who responded to it". ${ }^{39}$ With regard to professional development, medical education faculty workshop participants have recognised the value of reflective writing as a vehicle for learning about their teaching practice and development, ${ }^{53}$ and a faculty development workshop on narrative medicine for reflecting on the use of narrative in professional practice has had measureable impacts. ${ }^{54}$ Recently, a faculty development programme using guided reflective writing promoted reflection and empathy among practicing physicians ${ }^{55}$ and the integration of written narratives (on meaningful clinical experiences) for reflection within a continuing education programme on mindful communication for primary care physicians helped cultivate intrapersonal and interpersonal mindfulness and improve their sense of well-being. ${ }^{56}$

While both the arts and narrative can foster reflection and cultivate aesthetic ways of knowing ${ }^{57}$ within medical education, their combined use within a faculty development paradigm has not, to the best of our knowledge, been reported in the literature. Our described workshop design, therefore, is offered as an innovative approach to facilitating reflection through the combined use of art and narrative within faculty development.

\section{WORKSHOP DESCRIPTION}

Building on our foundational work on a previous occasion with integrating medical humanities in medical education, ${ }^{18}$ we (KK and OCC) designed a workshop for the 2012 WONCA (World Organization of National Colleges, Academies and Academic Associations of General Practitioners/Family Physicians) Conference (Vienna, Austria) to enhance the reflective competence of family medicine educators in the context of the educator-learner relationship. At the conclusion of the workshop, it was anticipated that participants would be able to identify challenges in educator-learner relationships, describe emotions emerging during an educational interaction with a learner, and utilise reflective writing as a strategy for addressing and managing challenges in educator-learner relationships.

At the beginning of the workshop, the facilitators (KK and OCC) presented the rationale and plan for the workshop, and requested and obtained the verbal informed consent of the participants for potential publication of the results of the workshop. Participants were free to engage in the workshop, and all of them agreed to take part and gave their consent verbally for potential publication of the results, including anonymous 
citations of their responses (which were openly and visibly transcribed by facilitator OCC throughout the workshop).

In the first part of the workshop, three abstract paintings were presented to the group using PowerPoint slides. The paintings presented were: 'Red and Orange' by Mark Rothko, 'Full Fathom Five' by Jackson Pollock, and 'Composition number 6' by Vassily Kandinsky. After observing the paintings one by one, participants were asked to choose one of the paintings to focus on. Each participant was provided with a small photograph of his or her selected painting $(10 \mathrm{~cm} \times 7 \mathrm{~cm})$. They were then instructed to observe the painting again and to let the painting 'work' on them, allowing emotions to emerge spontaneously, rather than asking themselves what they saw in the painting.

After several minutes of quiet contemplation, participants were invited to describe the emotions that emerged while observing the painting. Next, while gazing at the painting and allowing their emotional response to accompany the writing exercise, participants were asked to write a personal narrative either in their native language or in English, describing a meaningful or challenging situation with a student or a resident. Participants were then asked to share their narratives in pairs. After hearing the narrative, the listener was instructed to ask reflection-inviting questions to promote depth and breadth of reflection. The participant pairs then switched roles. Questions promoting reflective thinking included:

1. What ambiguity or contradiction, if any, was reflected in the narrative?

2. Where does this narrative take us? What challenges emerged within the narrative?

3. How did the narrative contribute to meaning-making?

4. How might you do things differently in the future?

5. What could be an action plan?

\section{RESULTS}

Twenty-three family medicine physicians or physicians-in-training from 10 countries participated in the workshop: 13 women and 10 men. Countries represented included Austria, Ireland, Israel, the Netherlands, New Zealand, Norway, Romania, Singapore, Spain and the UK.

In the final part of the workshop, the participants were asked to share their feedback and take-home messages with the group. The discussion was recorded and transcribed. Emerging themes were coded by the authors independently and discussed to achieve mutual agreement. Themes are presented below with accompanying exemplars of workshop participants' responses.

1. Narratives from different countries are similar: "Same stories. The relations with trainees-giving feedback-put stress in relations".

2. The use of art helped access feelings: "The paintings gave us the right mood, the right words to talk about challenges", "The colors make balanced emotions and free your mind".

3. Viewing abstract paintings facilitated next steps: "Looking at abstract paintings-it is like you have pushed a button which opens a door that leads to the story. It has opened the right side of the brain which allowed your left side to work better".

4. Writing reflective narratives promoted examination of educational challenges, compassion for self and other (regarding challenging feedback sessions), and building an action plan "The writing helped me organize and find a solution", and "Very therapeutic. I wrote on a bad experience but at the end we were laughing at it".

5. Sharing of narrative was helpful for fostering active listening and appreciating multiple perspectives: "Listening was a challenge. Trying to see another point of view. The experience was a lesson to me".

\section{DISCUSSION}

We designed and conducted an innovative faculty development workshop to foster reflective capacity using art and narrative. We hypothesised that the combined use of abstract art and writing reflective narratives would have an added value in achieving the goal of facilitated reflection. While the value of reflective writing within medical education is now widely recognised and successfully implemented within curricula, ${ }^{14-16}$ we were uncertain about the acceptability of an intervention utilising abstract paintings and its impact. To the best of our knowledge, our innovation of using abstract paintings to foster reflection within faculty development is novel. However, we can only speculate how the use of this innovative approach in addition to the complexity of viewing and appreciating abstract painting, is perceived by workshop participants.

Several themes emerged from the workshop discussion and are discussed below.

\section{Participants felt that narratives from different countries were similar}

While teaching methods in the context of educator-learner relationships in family medicine/general practice may differ, it was not surprising that the narratives were similar given that most countries represented in the workshop have Western cultural and medical education orientations.

\section{The use of art helped access feelings and viewing abstract paintings facilitated next steps}

Physiologically, it is unclear how looking at abstract paintings contributes to reflection. In his book 'The Age of Insight', the neuroscientist and Nobel Prize winner Eric Kandel explains how our brains perceive and engage with art, and how we are moved by it. He cites the Swiss-German art historian Wilhelm Worringer, who argues that two sensitivities are required of the viewer: empathy, which allows the viewer to lose herself in a painting and be at one with the subject, and abstraction, which allows the viewer to retreat from the complexities of the everyday world and follow the symbolic language of the forms and colours in a painting. ${ }^{58}$ Kendel cites Solso, who argues that in viewing abstract paintings, the viewer is trying to find a "deeper" meaning in each of the limited number of features, and thus spends more time on each. ${ }^{59}$ This could conceivably relate to the viewing of abstract paintings in the workshop facilitating participants' 'right mood' and transition to reflective writing.

\section{Writing reflective narratives promoted examination of educational challenges, and compassion for self and other}

Reflection-fostered through the vehicle of reflective writingcan contribute to the professional development of teachers ${ }^{60}$ including "examination of educational challenges". Reflection-in-action helps maintain flexibility during teaching and reflection-on-action promotes thoughtful analysis of the teaching experience for an ongoing iterative process of observing, reflecting and experimenting. Critical reflection can help teachers avoid being "trapped in unexamined judgments, interpretations, assumptions, and expectations" ${ }^{61}$ and thus potentially enrich teaching practice. In addition, cultivating awareness of self and other through reflective writing can nurture empathy ${ }^{55}$ and self-compassion, which includes recognition of shared humanity. ${ }^{62}$ 


\section{Sharing of narrative was helpful for fostering active listening and appreciating multiple perspectives}

Reflective writing in small group process within medical education can promote reflective self-assessment for personal and professional development. ${ }^{27}$ The sharing of narratives within a small group has been described as a "springboard to deeper discussion and reflection". ${ }^{15}$ A core process of the reflection construct fostered through reflective writing in small group process is appreciating multiple perspectives (within a disorienting dilemma), contributing to meaning-making. ${ }^{63}$

To summarise, qualitative assessment of the workshop indicated that the combined use of art and narrative was well received and perceived as contributing to the reflective exercise. Participants generally felt that viewing abstract paintings had facilitated a valuable mood transformation and prepared them emotionally for the reflective writing and the reflective exercise.

At this level of evaluation, we cannot judge the long term impact of this faculty development session on the reflective capacity of medical educators. In line with participants' workshop experiences and their feedback, we may speculate that some impact on their personal and professional development and on skills as 'reflective role models' within teaching has been achieved.

Our study has several limitations. We conducted a single arts-narrative-based intervention on a relatively small number of participants. In addition, we did not use a control group receiving a non-arts-based or a figurative arts-based intervention. Neither attitude nor behavioural changes arising from our workshop using a combination of validated qualitative methods were assessed.

\section{CONCLUSION}

A faculty development workshop using art and reflective narrative to foster reflective capacity in medical educators in the context of educator-learner relationships is feasible and valuable. Faculty participants felt that the use of abstract paintings had contributed to facilitating the reflective writing and the reflective exercise. The study shows that such a workshop can be easily conducted for faculty development by facilitators without formal education in the arts or literature. Recommendations for future research might include comparing arts-narrative-based workshops with a control group using only reflective narrative or in combination with figurative art and implementing a combination of qualitative and quantitative methods of assessment.

Contributors All authors meet the ICJME requirements for authorship. Namely, all three have met the following conditions: (1) substantial contributions to conception and design, acquisition of data, or analysis and interpretation of data; (2) drafting the article or revising it critically for important intellectual content; and (3) final approval of the version to be published.

\section{Competing interests None.}

Provenance and peer review Not commissioned; externally peer reviewed.

Open Access This is an Open Access article distributed in accordance with the Creative Commons Attribution Non Commercial (CC BY-NC 3.0) license, which permits others to distribute, remix, adapt, build upon this work non-commercially, and license their derivative works on different terms, provided the original work is properly cited and the use is non-commercial. See: http://creativecommons.org/ licenses/by-nc/3.0/

\section{REFERENCES}

1 Mann K, Gordon J, MacLeod A. Reflection and reflective practice in health professions education: a systematic review. Adv Health Sci Educ Theory Pract 2009;14:595-621.

2 ACGME. http://www.acgme.org/acgmeweb/Portals/0/PDFs/commonguide/IVA5C_ EducationalProgram_ACGMECompetencies_PBLI_Documentation.pdf (Accessed 10 Sept 2013).
3 Tomorrow's Doctors. General Medical Council, United Kingdom, 2009.

4 Schon DA. The reflective practitioner: how professionals think in action. New York, NY: Basic Books, 1983.

5 Boud D, Keogh R, Walker D, eds. Reflection: turning experience into learning. London: Kogan Page, 1985.

6 Epstein R. Mindful practice. JAMA 1999;282:833-9.

7 Dasgupta S, Charon R. Personal illness narratives: using reflective writing to teach empathy. Acad Med 2004;79(4):351-6.

8 Wald HS, Reis SP. Beyond the margins: reflective writing and development of reflective capacity in medical education. J Gen Intern Med 2010;25(7):746-9.

9 Bing-You RG, Trowbridge RL. Why medical educators may be failing at feedback. JAMA 2009;302(12):1330-1.

10 Nothnagle M, Goldman R, Quirk M, et al. Promoting self-directed learning skills in residency: a case study in program development. Acad Med 2010;85:1874-9.

11 George $P$, Reis $S$, Nothnagle $M$. Using a learning coach to teach residents evidence-based medicine. Fam Med 2012;44(5):351-5.

12 Jay JK, Johnson KL. Capturing complexity: a typology of reflective practice for teacher education. Teach Teach Educ 2002;18:73-85.

13 Tremmel R. Zen and the art of reflective practice in teacher education. Harv Educ Review 1993;4:434-58.

14 Charon R. The physician-patient relationship: narrative medicine: a model for empathy, reflection, profession, and trust. JAMA 2001;286:1897-902.

15 Wald HS, Davis SW, Reis SP, et al. Reflecting on reflections: medical education curriculum enhancement with structured field notes and guided feedback. Acad Med 2009;84(7):830-7.

16 Levine RB, Kern DE, Wright SM. The impact of prompted narrative writing during internship on reflective practice: a qualitative study. Adv Health Sci Educ Theory Pract 2008;13(5):723-33.

17 Charon R. Narrative Medicine: Honoring the Stories of IIIness. New York, NY: Oxford University Press, 2006

18 Karkabi K, Castel Cohen 0. Teaching reflective competence in medical education using paintings. Med Humanit 2011;37:58-9.

19 Pellico LH, Friedlaender L, Fennie KP. Looking is not seeing: using art to improve observational skills. J Nurs Educ 2009;48(11):648-53.

20 Wald HS, Norman DR, Walker J. Reflection through the arts: focus on photography to foster reflection in a health care context. Living Beyond-an interactive photographic exhibit. Reflective Pract 2010;11(4):545-62.

21 Shapiro J, Coulehan J, Wear DM, et al. Medical humanities and their discontents: definitions, critiques, and implications. Acad Med 2009;84(2):192-8.

22 Hunter KM, Charon $\mathrm{R}$, Coulehan JL. The study of literature in medical education. Acad Med 1995;70(9):787-94.

23 Frank A. Asking the right question about pain: narrative and phronesis. Lit Med 2004;23(2):209-25.

24 Wald HS. Insights into professional identity formation in medicine: memoirs and poetry. Eur Legacy 2011;16(3):377-84.

25 Reis SP, Wald HS, Monroe AD, et al. Begin the BEGAN (The Brown Educational Guide to the Analysis of Narrative). A framework for enhancing educational impact of faculty feedback to students' reflective writing. Patient Educ Couns 2010;80 (2):253-9.

26 Wald HS, Reis SP, Monroe AD, et al. "The Loss of My Elderly Patient": interactive reflective writing to support medical students' rites of passage. Med Teach 2010;32 (4):e178-84.

27 Shapiro J, Kasman D, Shafer A. Words and wards: a model of reflective writing and its uses in medical education. J Med Humanit 2006;27(4):231-44.

28 Cohen-Sayag E, Fischl D. Reflective writing in pre-service teachers' teaching: what does it promote? Aust J Teach Educ 2012;37.

29 Law S. Using narratives to trigger reflection. Clin Teach 2011;8:147-50.

30 Clandinin DJ, Cave MT. Creating pedagogical spaces for developing doctor professional identity. Med Educ 2008;42(8):765-70.

31 Bardes C, Gillers D, Herman A. Learning to look: developing clinical observational skills at an art museum. Med Educ 2001;35:1157-61.

32 Shapiro J, Rucker L, Beck J. Training the clinical eye and mind: using the arts to develop medical students' observational and pattern recognition skills. Med Educ 2006; $40: 263-8$

33 Dolev J, Friedlander L, Braverman I. Use of fine arts to enhance visual diagnostic skills. JAMA 2001;286:1020-1.

34 Naghshineh S, Hafler JP, Miller AR, et al. Formal art observation training improves medical students' visual diagnostic skills. J Gen Med 2008;23(7):991-7.

35 Reilly JM, Ring J, Duke L. Visual thinking strategies: a new role for art in medical education. Fam Med 2005;37(4):250-52.

36 Karkabi K, Cohen Castel O. Deepening compassion through the mirror of painting Med Educ 2006:40:462

37 Gaufberg E, Williams R. Reflection in a museum setting: the personal responses tour. J Grad Med Educ 2011;3(4):546-9.

38 Wald HS. Fostering reflective capacity through interactive reflective writing in health professions' education. Visiting Scholar Interprofessional Workshop, University of Western Ontario, June 8, 2010. http://www.edu.uwo.ca/inspire/wald_talk.html (accessed 10 Sept 2013). 
39 Wald HS. The "Parallel 'Parallel Chart'". http://medhum.med.nyu.edu/blog/?p=535 (accessed 10 Sept 2013).

40 Hurwitz B. Medicine, the arts, and humanities. Clin Med 2003:3(6):497-98.

41 Sandars J, Murray C. Digital storytelling for reflection learning in undergraduate medical education: a pilot study. Educ Prim Care 2009;20:441-44.

42 Brand G, McMurray A. Reflection on photographs. J Gerontol Nurs 2009;35(11):30-7.

43 Karkabi K, Cohen Castel O. Suffering and compassion in painting: the gift of art. IMAJ 2007:9:419-23.

44 Downie RS. The Healing Arts. Oxford University Press, 2000.

45 Berger J. Ways of seeing. Harmondsworth: Penguin, 1972.

46 Leder $\mathrm{H}$, Belke B, Oeberst A, et al. A model of aesthetic appreciation and aesthetic judgments. Br J Psychol 2004;95:489-508.

47 Zeki S. Statement on neuroesthetics. Nov 24, 2009. http://www.neuroesthetics.org/ statement-on-neuroesthetics.php (accessed 10 Sept 2013).

48 Austen K. Get the picture? Art in the brain of the beholder. New Scientist 17 July 17 2012. http://www.newscientist.com/article/mg21528732.

000-get-the-picture-art-in-the-brain-of-the-beholder.html (accessed 10 Sept 2013).

49 Boddy-Evans M. Abstract art: an introduction to abstract art and painting: what it is, how it developed. About.com Guide. http://painting.about.com/od/abstractart/a/ abstract_art.htm (accessed 10 Sept 2013).

50 Csikszentmihalyi M. Implications of a systems perspective for the study of creativity. In: Sternberg RJ. ed. Handbook of creativity. Cambridge: Cambridge University Press, 1999:313-35.

51 Bernard AW, Greenberger S, Gorgas D, et al. The use of reflection in emergency medicine education. Acad Emerg Med 2012;19(8):978-82.

52 Wald HS, Borkan JM, Reis SP, et al. Faculty development for enhancing feedback to medical students' reflective narratives: formal analytic frameworks for fostering and evaluating reflective capacity through "interactive" reflective writing. Oral presentation. 1st International Conference on Faculty Development in the Health Professions. University of Toronto, May 10, 2011

53 Miles E. Reflective writing in a faculty development program-challenges and rewards. Oral presentation. 1st International Conference on Faculty Development in the Health Professions. University of Toronto, May 10, 2011.

54 Liben S, Chin K, Boudreau D, et al. Assessing a faculty development workshop in narrative medicine. Med Teach 2012;34:e813-19.

55 Misra-Hebert AD, Isaacson $H$, Kohn $M$, et al. Improving empathy of physicians through guided reflective writing. Int J Med Educ 2012;3:71-7.

56 Beckman HB, Wendland M, Mooney $C$, et al. The impact of a program in mindful communication on primary care physicians. Acad Med 2012;87(6): 815-19.

57 Charon R. Commentary on "Creative expressive encounters in health ethics education: teaching ethics as relationship engagement". Teach Learn Med 2009; 21(2):163-5

58 Kandel ER. The age of insight. New York: Random House, 2012

59 Solso RL. Cognition and the visual arts. Cambridge, MA: MIT Press, 1994.

60 Pinsky LE, Monson D, Irby DM. How excellent teachers are made: reflecting on success to improve teaching. Adv Health Sci Educ Theory Prac 1998;3(3):207-15.

61 Larrivee B. Transforming teacher practice: becoming the critically reflective teacher. Reflective Pract 2000;1:293-315.

62 Neff K. Embracing our common humanity with self-compassion. http://www. huffingtonpost.com/kristin-neff/self-compassion_b_1889880.html (accessed 10 Sept 2013).

63 Wald HS, Borkan JM, Taylor JS, et al. Fostering and evaluating reflective capacity in medical education: development of the REFLECT (Reflection Evaluation for Learners' Enhanced Competencies Tool) rubric for evaluating students' reflective writing. Acad Med 2012;87(1):41-50 